\title{
Study on Model Reference Fuzzy Adaptive Control for Sensorless Vector Controlled Induction Motor Drives
}

\author{
Lin Jiang \\ School of Electrical Engineering and Information \\ Southwest Petroleum University \\ Chengdu 610500, China \\ jlin@swpu.edu.cn \\ Ke Chen \\ School of Electrical Engineering and Information \\ Southwest Petroleum University \\ Chengdu 610500, China \\ ck86y@qq.com
}

\author{
Jun $\mathrm{Wu}$ \\ School of Electrical Engineering and Information \\ Southwest Petroleum University \\ Chengdu 610500, China \\ 924246759@qq.com \\ Qing Yang \\ School of Electrical Engineering and Information \\ Southwest Petroleum University \\ Chengdu 610500, China \\ 81837928@qq.com
}

\begin{abstract}
In this paper, a model reference fuzzy adaptive system (MRFAS) control method using on-line self tuning fuzzy quantizing and scaling factors is applied to the sensorless vector controlled induction motor (IM) drive system with MRAS type speed estimator. In this method, a stator current model based MRFAS observer is presented to estimate the rotor speed and inverse rotor time constant and rotor flux is estimated using the MRAS ${ }^{\mathrm{CC}}$ estimator. A novel nonlinear adaptation mechanism is proposed in which the speed adaptation scheme and the other of inverse rotor time constant are executed by two-stage fuzzy logic controllers with self-tuned parameters based on the error and change of error measured between the actual current and the reference model output signal. Simulation results are presented to validate the effectiveness of the proposed method, showing stable system responses almost insensitive to large parameter variations.
\end{abstract}

Keywords-Induction motor; model reference fuzzy adaptive system; rotor time constant; vector control; self-tuning fuzzy control

\section{INTRODUCTION}

All Induction motors (IMs) are widely used in industry and many other fields due to its robustness, reliability, low price and free maintenance. And speed sensorless vector controlled IM drives are being vigorously developed for high performance industrial drive systems in the past decades. Most of the sensorless control techniques are dependent on motor parameters, such as stator resistance, inductance, and rotor time constant [1]. Thus, the performance suffers greatly in harsh and highly dynamic operating conditions, where the motor parameters are changing. Model reference adaptive system (MRAS) based observers, which is one of the best methods to estimate the rotor speed, are well-established sensorless techniques that have attracted much attention due to its performances and straight forward stability [2-5]. Compared with the classical rotor flux based MRAS scheme (MRASF), stator current based MRAS Estimator (MRASCC) has a wider speed adjustment range [2]. Nevertheless, the MRASCC estimator is sensitive to the changes in the rotor time constant which vary during operation of the machine due to ohmic heating [4]. If rotor parameter error exists, it does not only change the achieved rotor speed, but it also changes the dynamic behavior of the whole field oriented control [5]. Therefore, the on-line rotor time constant estimation is inevitable to guarantee a competent performance in the IM drives. Several strategies have been proposed for rotor time constant estimation in the vector controlled IM drives [4, 6-8]. Among these techniques, MRAS based schemes are the most common strategies employed due to their relative simplicity and low computational effort $[4,8]$.

The majority of adaptation schemes described in the literature for MRAS observers employ a proportionalintegral (PI) controller to generate the desired value However, fixed gain PI controllers may become unable to provide the required control performance due to the continuous variation in the motor parameters and the nonlinear operating conditions [9]. These inherent disadvantages of the PI controller have encouraged the replacement of the conventional PI controller with artificial intelligence-based controllers such as the fuzzy logic controller, fuzzy neural network and genetic algorithms [10-12]. In [13], an adaptive sliding-mode neuro-fuzzy controller is presented for the sensorless IM drive system with MRAS type speed estimator. Besides literature [14], not much attention has been devoted to study other types of adaptation mechanisms used to minimize the estimation of the inverse rotor time constant $(1 / \mathrm{Tr})$ variation. The performance of vector controlled IM drives to a large extent depends on the accuracy of inverse rotor time constant estimation which in turn mainly depends on the value of rotor resistance which varies with temperature. 
In this paper, a novel nonlinear adaptation mechanism is proposed to replace the classical PI controller used in the MRASCC observer. So, a novel type of model reference fuzzy adaptive system (MRFAS) based estimator which combines fuzzy logic control with MRASCC is introduced to identify the rotor speed and inverse rotor time constant of the vector controlled IM drives. In this method, a speed adaptive law based on parameter self-tuning fuzzy control is designed for the speed identification system, the other similar one is for the inverse rotor time constant identification, where the quantitative factors of input and output of those controllers are adjusted automatically. This estimation will assure a new robust adaptation method and improve the estimation performance. A performance comparison between the proposed controller and MRASCC scheme is accomplished by means of extensive simulations. The simulation results have proved the effectiveness of the proposed method, showing stable system responses almost insensitive to large parameter variations.

\section{THE DYNAMIC MODEL OF IM}

The overall dynamics of an IM in stationary reference frame under the assumptions of equal mutual inductances and linear magnetic circuits are given by the following complex stator voltage, stator current and flux linkage equations [1]:

$$
\begin{aligned}
\tau_{\sigma} p \boldsymbol{i}_{s}+\boldsymbol{i}_{s} & =\frac{k_{r}}{R_{\sigma} T_{r}}\left(1-j \omega_{r} T_{r}\right) \times \boldsymbol{\psi}_{r}+\frac{1}{R_{\sigma}} \boldsymbol{u}_{s} \\
T_{r} p \boldsymbol{\psi}_{r}+\boldsymbol{\psi}_{r} & =j \omega_{r} T_{r} \boldsymbol{\psi}_{r}+L_{m} \boldsymbol{i}_{s}
\end{aligned}
$$

where $\boldsymbol{u}_{s}=u_{s d}+j u_{s q}, \boldsymbol{i}_{s}=i_{s d}+j i_{s q}$ and $\boldsymbol{\psi}_{r}=\psi_{r d}+j \psi_{r q}$ are the stator voltage, stator current and rotor flux vectors, respectively; $\tau_{\sigma}=\sigma L_{\mathrm{S}} / R_{\sigma}$ is a transient stator time constant, $R_{\sigma}=R_{\mathrm{s}}+k_{\mathrm{r}}^{2} R_{\mathrm{r}}$ is an equivalent resistance, and $k_{r}=L_{\mathrm{m}} / L_{r}$ is the coupling factor of the rotor; $R_{s}$ and $R_{r}$ are the stator and rotor resistances, respectively; $L_{s}, L_{r}$ and $L_{m}$ are the self inductances of the stator and rotor, and the mutual inductance, respectively; $T_{r}=L_{r} / R_{r}$ is the rotor time constant, $\omega_{r}$ is the rotor speed, $p$ is differential algorithm.

\section{PARAMETRIC SENSITIVITY OF ROTOR FLUX OBSERVER AND MRFAS OBSERVER}

\section{A. Parametric sensitivity of rotor flux observer}

Current model based rotor flux observer for IM can be expressed by the following complex form:

$$
p \boldsymbol{\psi}_{r}=\frac{L_{m}}{T_{r}} \boldsymbol{i}_{s}+\left(-\frac{1}{T_{r}}+j \omega_{r}\right) \boldsymbol{\psi}_{r}
$$

The above rotor flux estimator can work in full speed range, but it is greatly influenced by the rotor parameters. The equation (2) can be obtained from the Laplace transform:

$$
\boldsymbol{\psi}_{r}=\frac{L_{m}}{T_{r}} \frac{1}{\left(s+1 / T_{r}-j \omega_{r}\right)} \boldsymbol{i}_{s}
$$

When introducing $\mathrm{s}=j \omega_{1}$ in equation (3), it can then be converted to:

$$
\boldsymbol{\psi}_{r}=\frac{L_{m}}{1+j T_{r} \omega_{s}} \boldsymbol{i}_{s}
$$

where $\omega_{1}$ is the synchronous angular frequency, $\omega_{s}$ is the slip speed.

Similarly, the estimated rotor flux can be written as follows corresponding to the actual stator currents:

$$
\hat{\boldsymbol{\psi}}_{r}=\frac{\hat{L}_{m}}{1+j \hat{T}_{r} \omega_{s}} \boldsymbol{i}_{s}
$$

In this section, a relation between the estimated flux and the real flux will be built based on the equations of the IM in steady state [15], [16], defined as the ratio between the estimated rotor flux vector and the real one:

$$
\boldsymbol{\Phi}\left(j \omega_{s}\right)=\frac{\hat{\psi}_{r}}{\boldsymbol{\psi}_{r}}=\frac{\hat{L}_{m}}{L_{m}} \frac{\left(1+j T_{r} \omega_{s}\right)}{\left(1+j \hat{T}_{r} \omega_{s}\right)}
$$

It can be seen that the flux ratio depends on estimated and real parameters, on the slip speed $\omega$ s. Furthermore, the steady-state conditions are supposed to be set up. Consequently, the slip $\omega$ s is mainly affected by the load The rotor flux observer is only affected by the mutual inductance $\mathrm{Lm}$ and rotor time constant $\mathrm{Tr}$. In practice, $\mathrm{Tr}$ can be changed with motor operating conditions. Without taking into account magnetic saturation (that is, assuming the mutual inductance is constant), equation (6) can be written as:

$$
\boldsymbol{\Phi}\left(j \omega_{s}\right)=\frac{\hat{\boldsymbol{\psi}}_{r}}{\boldsymbol{\psi}_{r}}=\frac{\left(1+j T_{r} \omega_{s}\right)}{\left(1+j \hat{T}_{r} \omega_{s}\right)}
$$

The normalized amplitude and phase of the flux ratio is obtained by the following relation

$$
\begin{gathered}
\left|\boldsymbol{\Phi}\left(j \omega_{s}\right)\right|=\left|\frac{\hat{\psi}_{r}}{\psi_{r}}\right|=\frac{\sqrt{1+\left(L_{r} T_{N} T_{p u} / n_{p} \psi_{r e f}^{2}\right)^{2}}}{\sqrt{1+\left(L_{r} \hat{T}_{r} T_{N} T_{p u} / n_{p} \psi_{r e f}^{2} T_{r}\right)^{2}}} \\
\angle \boldsymbol{\Phi}\left(j \omega_{s}\right)=\operatorname{arctg}\left(\frac{L_{r} T_{N}}{n_{p} \psi_{r e f}^{2}} T_{p u}\right)-\operatorname{arctg}\left(\frac{L_{r} T_{N} \hat{T}_{r}}{n_{p} \psi_{r e f}^{2} T_{r}} T_{p u}\right)
\end{gathered}
$$

where $T_{N}$ is the rated value of electromagnetic torque, $T_{p u}$ is the standardized electromagnetic torque compared to its rated value.

Fig .1 shows the sensitivity of flux amplitude and phase in relation to errors on $T_{r}$ and depending on the mechanical speed and on the electromagnetic torque. To obtain this, an error of $50 \%$ is introduced into the parameter which is under consideration.

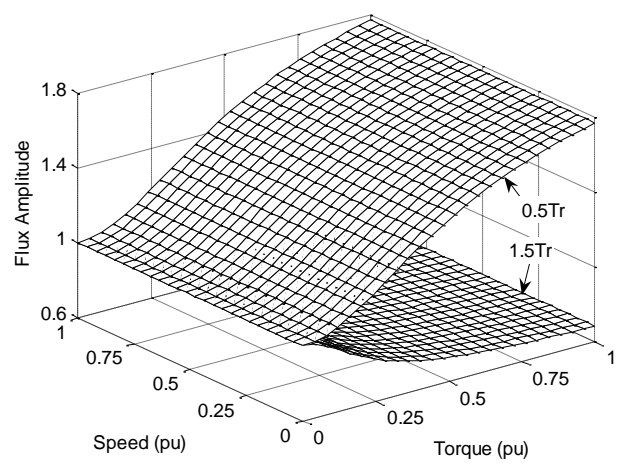

(a) Flux magnitude 


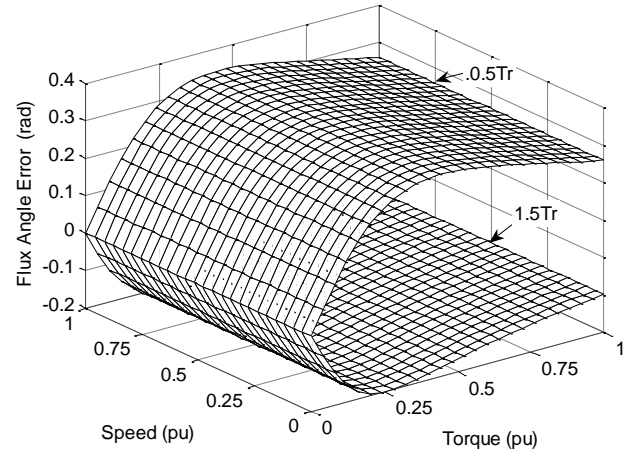

(b) Flux phase angle

Figure 1. Sensitivity of flux amplitude and phase to uncertainties on $T_{\mathrm{r}}$

As it is possible to see, an error on the rotor time constant $T_{r}$ has obviously influence on the flux value when load torque changes, while it almost does not affect the flux amplitude and phase when speed grows. An amplitude of the estimated rotor flux is greater than the real one and the estimated flux phase leads the real value when $\hat{T}_{r}$ is less than $T_{r}$. Whereas, an amplitude of the estimated rotor flux is less than the real one and the estimated phase angle lags behind the real value when $\hat{T}_{r}$ is greater than $T_{r}$. Accordingly, an error on the rotor time constant will affect the observation accuracy of rotor flux, and destroy the stator current decoupling, which affects the dynamic performance of the rotor field oriented control system.

\section{B. MRFAS observer}

Using the stator model (SM) of IM [1], the estimated values of the stator current vector is obtained in accordance with (1).

$$
\tau_{\sigma}^{\prime} \frac{\mathrm{d} \hat{\boldsymbol{i}}_{s}}{\mathrm{~d} t}+\hat{\boldsymbol{i}}_{s}=\frac{k_{r}}{R_{\sigma} T_{r}}\left(1-j \hat{\omega}_{r} T_{r}\right) \times \hat{\boldsymbol{\psi}}_{r}+\frac{1}{R_{\sigma}} \boldsymbol{u}_{s}
$$

where $\hat{i}_{s}$ and $\hat{\psi}_{r}$ are the estimated values of the stator current and rotor flux linkage vector, respectively; is the estimated rotor speed.

The described stator-current model requires information about the rotor-flux vector. This state variable is calculated on the basis of the speed dependent current model of the rotor flux [2], [17], i.e.,

$$
T_{r} \frac{\mathrm{d} \hat{\boldsymbol{\psi}}_{r}}{\mathrm{~d} t}+\hat{\boldsymbol{\psi}}_{r}=L_{m} \boldsymbol{i}_{s}+j \hat{\omega}_{r} T_{r} \hat{\boldsymbol{\psi}}_{r}
$$

The schematic diagram of the proposed MRFAS observer is shown in Fig .2, in which the induction motor is used as a reference system, and the current-flux model (CM) together with the current estimator (SM) are adjustable models. Both stator-current model (10) and rotor-flux model (11) are adjusted by the estimated rotor speed, where the used speed adaptation algorithm is different from the classical solution and is based on the error $\Delta \boldsymbol{i}_{s}=\hat{\boldsymbol{i}}_{s}-\boldsymbol{i}_{s}$ between estimated and measured stator current. Moreover, an estimate of the inverse rotor time constant is obtained using a MRAS in a fuzzy control scheme.

Supposing that $\hat{\tau}_{r}=1 / \hat{T}_{r}$, the adaptive control law of speed and the other of inverse rotor time constant are deduced by using Popov stability theorem:

$$
\begin{aligned}
& \hat{\omega}_{r}=\left(k_{p}+\frac{k_{i}}{s}\right)\left[\left(i_{s d}-\hat{i}_{s d}\right) \hat{\psi}_{r q}-\left(i_{s q}-\hat{i}_{s q}\right) \hat{\psi}_{r d}\right] \\
& \hat{\tau}_{r}=\left(k_{\tau p}+\frac{k_{\tau i}}{s}\right)\left[\left(\hat{i}_{s d}-i_{s d}\right)\left(L_{m} \hat{i}_{s d}-\hat{\psi}_{r d}\right)+\left(\hat{i}_{s q}-i_{s q}\right)\left(L_{m} \hat{i}_{s q}-\hat{\psi}_{r q}\right)\right]
\end{aligned}
$$

It is proved that the system can be asymptotically stable using this adaptation mechanism, and the adjustable model converges to the reference model, detailed refer to [2]. However, the control performance of PI regulator is depend on accurate mathematical model of induction motor, so it is difficult to obtain ideal control effects when the motor parameters change. In order to solve this problem, this paper proposes a parameter self-tuning fuzzy controller to replace the traditional PI controller.

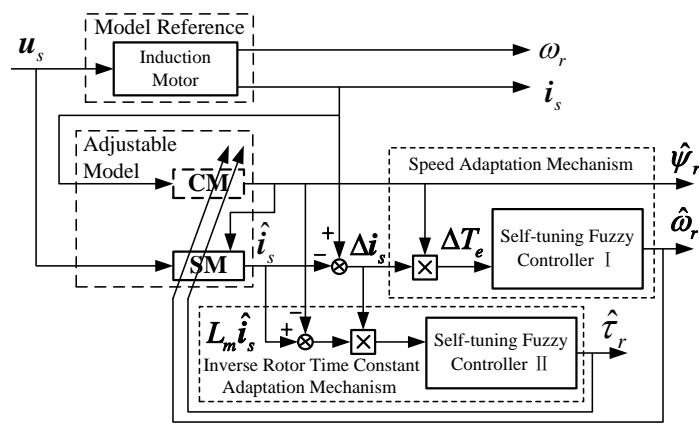

Figure 2. Proposed MRFAS observer

\section{Self-tuning Fuzzy Controller}

This paper designs a two-stage fuzzy controller with self-tuned parameter in order to overcome the shortage of fixed quantization factors and scaling factor that exist in general fuzzy controller, the block diagram of the proposed fuzzy controller is shown in Figure 3. This fuzzy controller has two inputs and one output, where its input arguments are the error $\mathrm{E}$ and the error change rate $\mathrm{EC}$, output argument is $\mathrm{u}$.

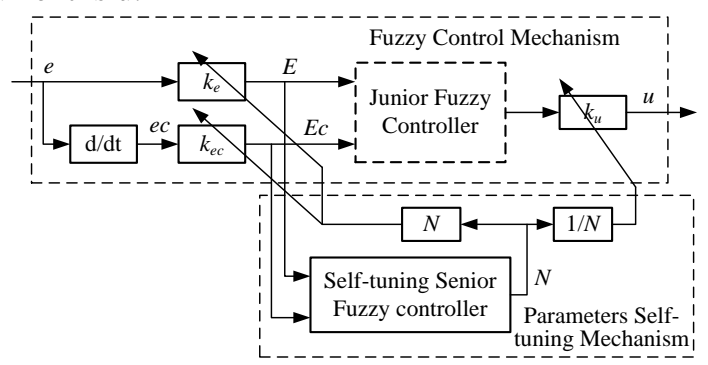

Figure 3. Block diagram of self-tuning fuzzy controller

Firstly, the fuzzy control rules and the original quantizing and scaling factors are designed for speed adaptation mechanism. Assuming that the domain of input deviation $e_{w}$ is $[-120,120]$, the domain of input deviating change rate $e c_{w}$ is $[-20,20]$, the domain of output $u$ is [-6, 6]. The fuzzy sets of E, EC, u, are \{ NB (negative big), NM (negative medium), NS (negative small), Z (zero), PS (positive small), PM (positive middle), PB (positive big)\}, while the field is $(-6,6)$. The original quantizing and scaling factors include: $k_{e}=1 / 20, k_{e c}=3 / 10, k_{u}=1$.

In this article, the membership functions are chosen as the triangular type, and the method of reasoning is 
considered as the max-min method, the defuzzification stage is done based on the gravity centre method, as it is frequently quoted in the literature and because they requiring less time computing will be also adopted in our work [8, 9]. The format of the fuzzy control rule is described as "if $E$ and $E c$ then $u$ ", whose fuzzy logic controller rules shown in Table I .

TABLE I. PI-TYPE FUZZY LOGIC CONTROLLER RULES

\begin{tabular}{c|c|c|c|c|c|c|c}
\hline \hline $\begin{array}{l}u \\
E C\end{array}$ & NB & NM & NS & ZE & PS & PM & PB \\
\hline NB & NB & NB & NM & NS & NS & NS & PM \\
NM & NB & NB & NM & NS & NS & ZE & PM \\
NS & NB & NM & NS & NS & ZE & PM & PM \\
ZE & NM & NM & NS & ZE & PS & PM & PB \\
PS & NM & NM & ZE & PS & PS & PM & PB \\
PM & NM & ZE & PS & PS & PM & PB & PB \\
PB & NM & PS & PS & PS & PM & PB & PB \\
\hline \hline
\end{tabular}

Similarly, the other fuzzy controller with the same structure and fuzzy logic controller rules is designed for inverse rotor time constant adaptation mechanism. Assuming that the domain of input deviation $e_{\tau}$ is $[-0.2$, $0.2]$, the domain of input deviating change rate $e c_{\tau}$ is [-0.1, $0.1]$, the domain of output $u$ is $[-1,1]$. The original quantizing and scaling factors are: $k_{e}=30, k_{e c}=60, k_{u}=1 / 6$.

It is well know that a change of quantizing and scaling factors of fuzzy controller will affect the dynamic and static characteristics of the controlled system. Therefore, an algorithm of self-tuning senior fuzzy controller is presented in this paper, according to the response of the system, which can adjust the quantizing factors of deviation $\mathrm{E}$ and deviation change rate Ec and the scaling factor of the actuating signal $u$ in the junior fuzzy controller on-line, as shown in Fig .3. The input variables of the senior fuzzy controller are still the deviation $\mathrm{E}$ and deviation change rate Ec, and its output is adjustable multiple $\mathrm{N}$, where the fuzzy logic controller rules are shown in Table II. The fuzzy sets of E, EC, are (NB, NM, NS, Z, PS, PM, PB $\}$, while the field is $(-6,6)$. The fuzzy sets of $\mathrm{N}$, are $\{\mathrm{CH}, \mathrm{CM}, \mathrm{CL}, \mathrm{C}, \mathrm{AL}, \mathrm{AM}, \mathrm{AL}\}$, while the field is $(1 / 8,8)$.

TABLE II. FUZZY RULES FOR SELF-TUNING SCALING FACTORS

\begin{tabular}{c|c|c|c|c|c|c|c}
\hline \hline$N=$ & NB & NM & NS & ZE & PS & PM & PB \\
\hline$C C$ & & & & & & & \\
\hline NB & CH & CM & CL & C & CL & CM & CH \\
NM & CM & CL & C & C & C & CL & CM \\
NS & CL & C & C & AM & C & C & CL \\
ZE & C & C & AL & AH & AL & C & C \\
PS & CL & C & C & AM & C & C & CL \\
PM & CM & CL & C & C & C & CL & CM \\
PB & CH & CM & CL & C & CL & CM & CH \\
\hline \hline
\end{tabular}

IV. SIMULATION RESUlTS

\section{A. Simulation Model}

The simulation has been performed for the verification of the proposed control algorithm. The simulation model is built by using matlab/simulink, as shown in Fig .4, which is located at the end of the article.

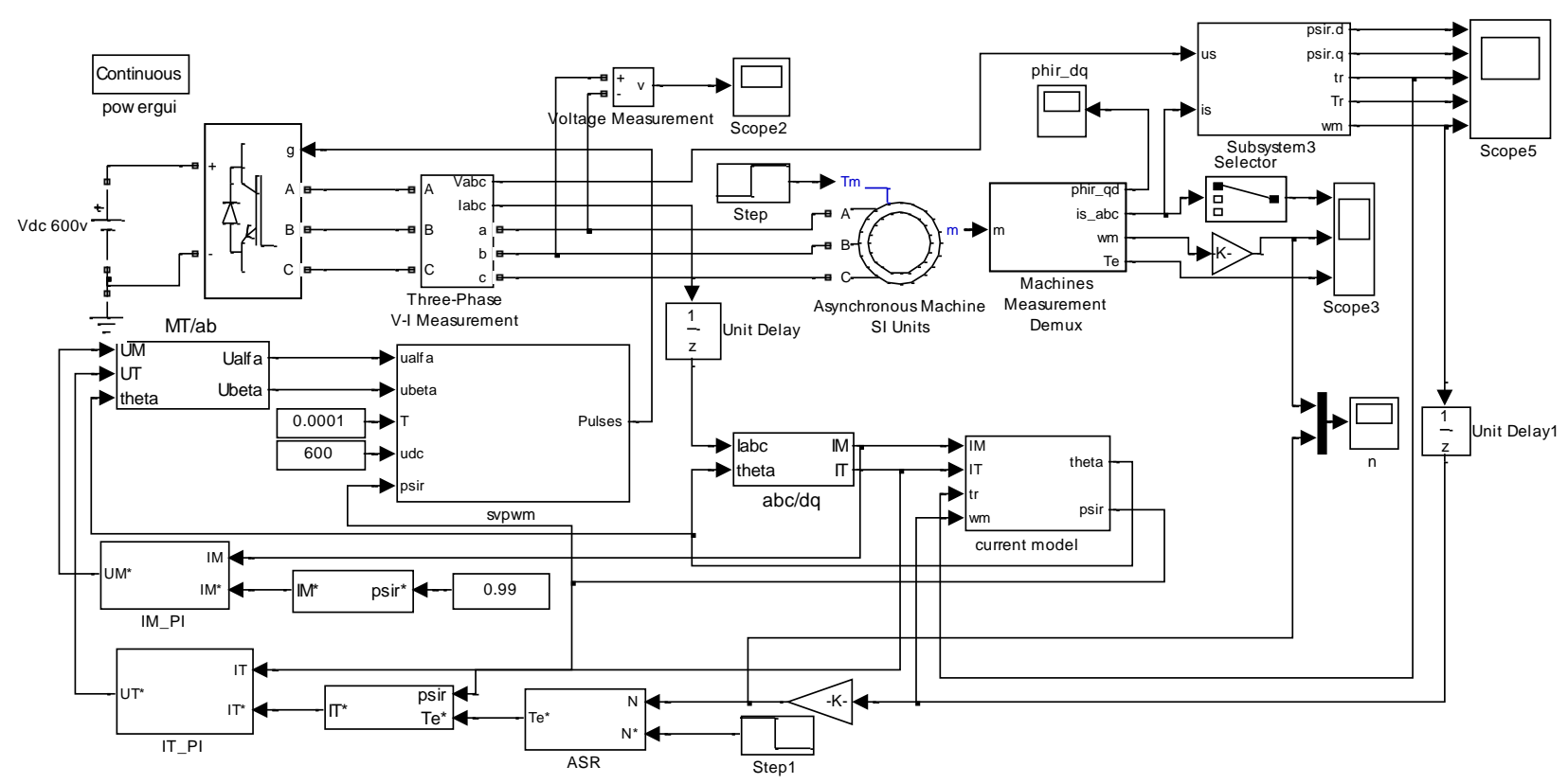

Figure 4. Simulation model of sensorless vector controlled IM drives based on MRFAS 
Table III shows the specification of induction motor used in the simulation.

TABLE III. MOTOR SPECIFICATION

\begin{tabular}{|c|c|c|c|}
\hline rated power & $15 \mathrm{~kW}$ & $R_{s}$ & $0.4 \Omega$ \\
\hline rated voltage & $380 \mathrm{~V}$ & $R_{r}$ & $0.5 \Omega$ \\
\hline rated current & $31 \mathrm{~A}$ & $L_{s}$ & $0.087 \mathrm{H}$ \\
\hline rated speed & $1460 \mathrm{rpm}$ & $L_{r}$ & $0.088 \mathrm{H}$ \\
\hline number of poles & 4 & $L_{m}$ & $0.085 \mathrm{H}$ \\
\hline
\end{tabular}

The $k_{p \omega}$ and $k_{i \omega}$ gains of speed PI regulator are chosen as follows: $k_{p \omega}=55, k_{i \omega}=0.1$; The $k_{\mathrm{p}}$ and $k_{\mathrm{i}}$ gains of both $\mathrm{t}$ and $\mathrm{m}$ axis current PI regulator are chosen as follows: $k_{p}=$ $20, k_{i}=5$.

\section{B. Simulation Results and Analysis}

Compared with the method proposed in literatures [2], [17], this paper obtains the simulation results under the same conditions, which are shown in Fig .5 and Fig .6, respectively. The figures show that these two kinds of sensorless vector controlled IM drives can be stable operation at low speeds of various working conditions, but the speed and rotor flux observations have some deviation based on the method in [2, 17], moreover, the rotor speed drops significantly when sudden loading, and there is a large speed overshoot when abrupt changing of speed; and the proposed method can better track the real values of the speed and rotor flux under various conditions, and the rotor speed drops smaller when sudden loading.
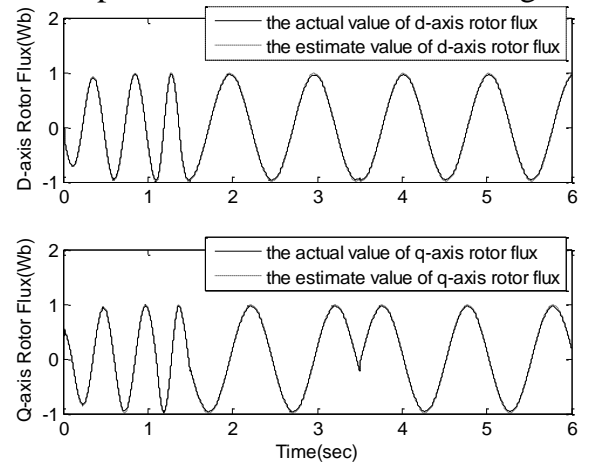

(a) Rotor flux

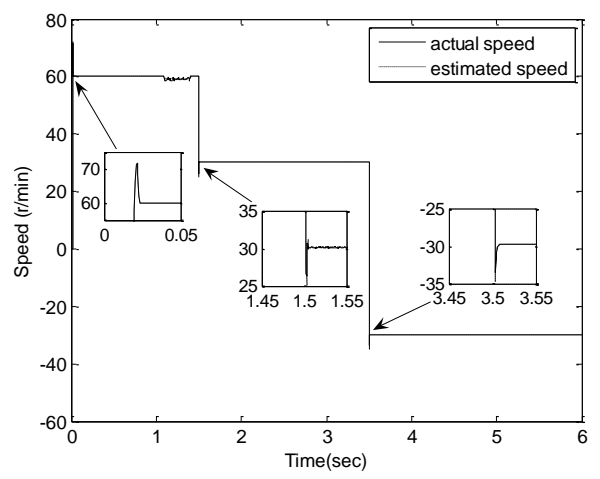

(b) Speed response

Figure 5. Dynamic response in MRAS ${ }^{\mathrm{CC}}$ system at low speed
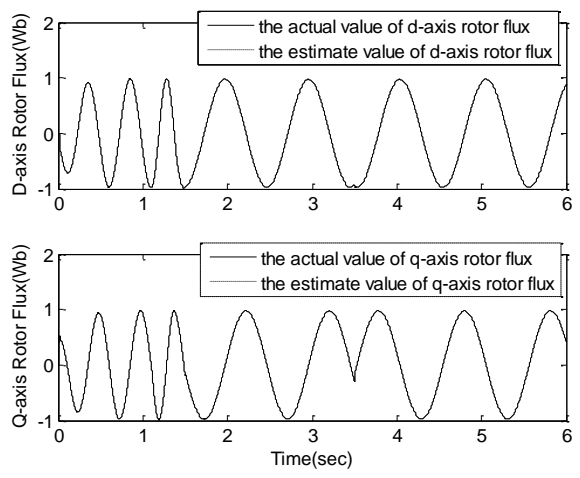

(a) Rotor flux

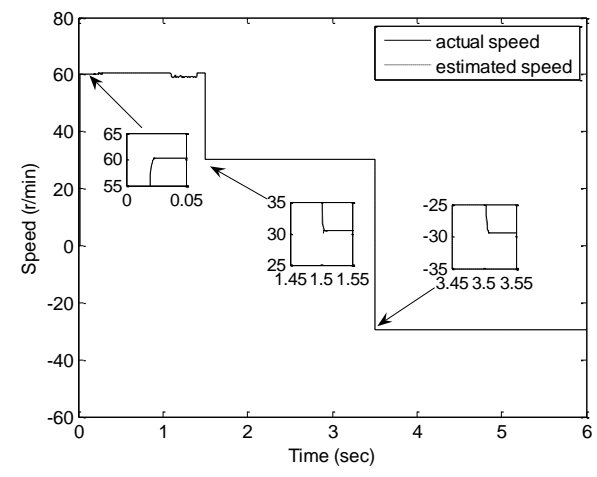

(b) Speed response

Figure 6. Dynamic response in MRFAS system at low speed

When $\hat{T}_{r}=0.5 T_{r}$ and $\hat{T}_{r}=1.5 T_{r}$, the sensorless vector controlled systems based on the MRFAS controller starts from a given speed 1200r/min without load and a sudden load $20 \mathrm{Nm}$ applied when $t=0.8 \mathrm{~s}$, and the load suddenly changes into 0 when $t=1.2 \mathrm{~s}$, meanwhile, the speed drops to $600 \mathrm{r} / \mathrm{min}$ when $t=1.5 \mathrm{~s}$. The dynamic response of the system is shown in Figure 7. It can be seen from the figure, both in high speed or low speed, the estimated speed is able to track the real value of rotor speed even when the load changes, regardless of the rotor time constant is too large or too small. And the steady state error and overshoot of the system is smaller, the proposed method has good adaptability and robustness.

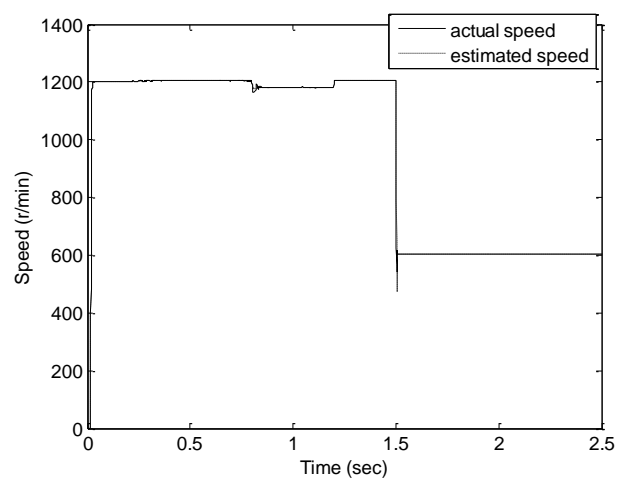

(a) Speed response at $0.5 T_{r}$ 


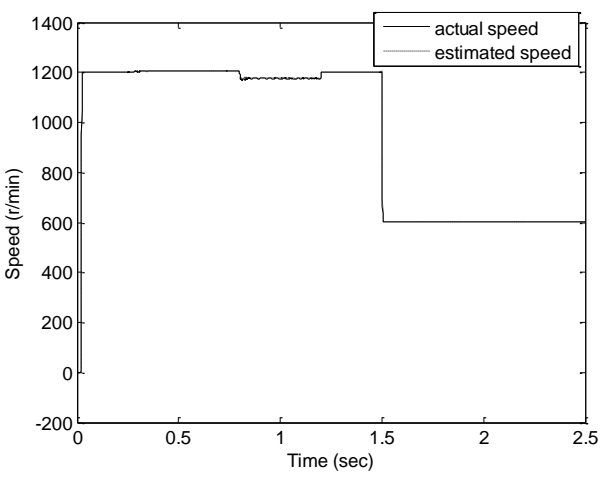

(b) Speed response at $1.5 T_{r}$

Figure 7. Speed response in MRFAS system with change of $T_{r}$

For the vector controlled IM drives, the rotor flux observer is increasingly sensitive to the deviation of rotor time constant when the load increases. Because of the MRFAS system introduces a self-tuning two-stage fuzzy controller which can dynamically adjust the quantizing and scaling factors, thus it makes the rotor time constant update online and the rotor flux observer runs more precisely. So, the proposed method has a good performance of speed tracking, and has a good robustness against rotor parameter perturbation.

\section{CONCLUSIONS}

In this paper, a MRFAS vector control system based on two-stage fuzzy controller with self-tuned parameter is proposed. In the MRFAS estimator, the induction motor is used as a reference system, and the current-flux model together with the current estimator are adjustable models. The sensitivity to inverse rotor time constant changes of the field-oriented IM drive is analysed. The presented approach has strong robustness and adaptability because of introducing rotor time constant online identification and self-tuning fuzzy controller. When the rotor time constant varies with the motor running condition, the rotor parameters can on-line identify and adjust in real time. Simulation results show that the system has excellent dynamic and steady state performance, and has stronger robustness and adaptability.

\section{ACKNOWLEDGMENT}

The research work was supported by National Natural Science Foundation of P.R. China under Grant No. 51204139 and Scientific Research Project of Sichuan Provincial Department of Education of China under Grant No. 13ZB0199.

\section{REFERENCES}

[1] J. Holtz, "Sensorless control of induction machines-with or without signal injection," IEEE Trans. on industrial electronics, vol.53, Feb. 2006, pp. 7-30, doi: 10.1109/TIE.2005.862324.

[2] T. Orlowska-Kowalska, M. Dybkowski, Stator-current-based MRAS estimator for a wide range speed-sensorless induction motor drive, IEEE Trans. on industrial electronics, vol.57, Sept. 2009, pp. 1296 - 1308, doi:10.1109/TIE.2009.2031134.
[3] S.M. Gadoue, D. Giaouris, J.W. Finch, "Stator current model reference adaptive systems speed estimator for regenerating-mode low-speed operation of sensorless induction motor drives," IET Electric Power Applications, vol.7, Aug. 2013, pp. 597-606, doi:10.1049/iet-epa.2013.0091.

[4] W.P. Rao, H.Q. Wan. "Parameter sensitivity of rotor time constant estimation based on MRAS for induction motors," Proc. IEEE 9th Conference on Industrial Electronics and Applications (ICIEA 2014), Hangzhou, China, 9-11 June, 2014, pp. 391- 394, doi:10.1109/ICIEA.2014.6931194

[5] M. Dybkowski, T. Orlowska-Kowalska, "Low-speed performance of the stator current-based MRAS estimator with FL controller in the sensorless induction motor drive," Proc. OPTIM 2008, Brasov, Romania. USA, 22-24 May, 2008, pp. 75-80, doi:10.1109/OPTIM.2008.4602460.

[6] Kaiyu Wang, J. Chiasson, M. Bodson, L.M. Tolbert, "An online rotor time constant estimator for the induction machine, IEEE Transactions on Control Systems Technology," vol.15, March 2007, pp. 339- 348,doi: 10.1109/TCST.2006.886445.

[7] Kai Wang, Bin Chen, Guangtong Shen, etc., "Online updating of rotor time constant based on combined voltage and current mode flux observer for speed-sensorless AC drives," IEEE Transactions on Industrial Electronics, vol.61, Nov. 2013, pp. 4583- 4593, doi:10.1109/TIE.2013.2288227

[8] A. Larabi, A. Amrane, M.S. Boucherit, "Robust speed sensorless fuzzy control of the induction machine drive with adaptation of the rotor time constant supplied by photovoltaic solar energy," Proc. International Conference on Power Engineering, Energy and Electrical Drives, PEEED-2013, Istanbul, Turkey,13-17, May, 2013, pp. 1398-1403,doi: 10.1109/PowerEng.2013.6635819.

[9] M.N. Uddin, T.S.Radwan, M.Rahman, "Performance of fuzzylogic-based indirect vector control for induction motor drive," IEEE Trans. Ind. Appl. vol. 38, Sep/Oct. 2002, pp. 1219-1225, doi:10.1109/TIA.2002.802990.

[10] Z. Ibrahim, E. Levi, "A comparative analysis of fuzzy logic and PI speed control in high performance ac drives using experimental approach,” IEEE Trans. Ind. Appl. vol. 38, Sep/Oct. 2002, pp.1210-1218, doi:10.1109/TIA.2002.802993.

[11] M. Nasir Uddin, Hao Wen, "Development of a self-tuned neurofuzzy controller for induction motor drives," IEEE Transactions on Industry Applications, vol. 43, July-aug. 2007, pp. 1108-1116,doi 10.1109/TIA.2007.900472.

[12] F. Lin, W. Chou, P. Huang, "Adaptive sliding mode controller based on real time genetic algorithm for induction motor servo drive," IEE Proc. Electr. Power Appl. vol. 150, Jan 2003, pp. 113, doi: 10.1049/ip-epa:20030053.

[13] T. Orlowska-Kowalska, M. Dybkowski, K. Szabat, "Adaptive sliding-mode neuro-fuzzy control of the sensorless induction motor drive with MRAS ${ }^{\mathrm{CC}}$ estimator," Proc. 13th European Conference on Power Electronics and Applications (EPE 09), 8-10 Sept Barcelona, Spanish, 2009, pp. 1-8.

[14] M. Sheela, S. Himavathi, S. Santhalakshmy, et al. "Comparison of flux and real power based MRAS for inverse rotor time constant estimation in induction Motor Drives," Proc. International Conference on Advances in Electrical Engineering, (ICAEE 2014 ), Vellore, Tamil Nadu, India, 9-11 Jan, 2014, pp.1-5,doi: 10.1109/ICAEE.2014.6838486.

[15] R. Benoît, F. Bruno, D. Philippe, et al. "Vector control of induction machines: desensitisation and optimisation through fuzzy logic," Springer, New York, 2012, doi: 10.1007/978-0-85729-901-7.

[16] H. Luo, "Research on the full-order flux observer and the speed estimation method of the induction motor," Huazhong University of Science and Technology PhD thesis, Wuhan, 2009, pp.45-49. (in Chinese)

[17] X.L. Ma, "How to extend speed range of speed—sensorless vector control drive systems of induction motors," Electric Drive, vol.41, no.1, 2011, pp3-8. (in Chinese) 